\title{
Intraoperative protective mechanical ventilation and risk of postoperative respiratory complications: hospital based registry study
}

\author{
Karim Ladha, ${ }^{1}$ Marcos F Vidal Melo, ${ }^{1}$ Duncan J McLean, ${ }^{1}$ Jonathan P Wanderer, ${ }^{2}$ \\ Stephanie D Grabitz, ${ }^{1}$ Tobias Kurth, 3, 4,5 Matthias Eikermann'1,6
}

'Department of Anesthesia, Critical Care, Pain Medicine, Massachusetts General Hospital, Boston, MA 02114 , USA

2Department of Anesthesiology, Vanderbilt University, Nashville, TN, USA

${ }^{3}$ INSERM Research Center for Epidemiology and Biostatistics (U897)-Team Neuroepidemiology, Bordeaux, France

${ }^{4}$ College of Health Sciences, University of Bordeaux,

Bordeaux, France

${ }^{5}$ Division of Preventive

Medicine, Brigham and

Women's Hospital, Harvard

Medical School, Boston, MA,

USA

${ }^{6}$ Essen-Duisburg University,

Essen, Germany

Correspondence to:

M Eikermann

meikermann@partners.org

Additional material is published online only. To view please visit the journal online (http://dx.doi. org/10.1136/bmj.h3646)

Cite this as: $B M J$ 2015;351:h3646 doi: 10.1136/bmj.h3646

Accepted: 25 June 2015

\section{ABSTRACT}

OBJECTIVE

To evaluate the effects of intraoperative protective ventilation on major postoperative respiratory complications and to define safe intraoperative mechanical ventilator settings that do not translate into an increased risk of postoperative respiratory complications.

DESIGN

Hospital based registry study.

SETTING

Academic tertiary care hospital and two affiliated community hospitals in Massachusetts, United States.

PARTICIPANTS

69265 consecutively enrolled patients over the age of 18 who underwent a non-cardiac surgical procedure between January 2007 and August 2014 and required general anesthesia with endotracheal intubation.

\section{INTERVENTIONS}

Protective ventilation, defined as a median positive end expiratory pressure (PEEP) of $5 \mathrm{~cm} \mathrm{H}_{2} \mathrm{O}$ or more, a median tidal volume of less than $10 \mathrm{~mL} / \mathrm{kg}$ of predicted body weight, and a median plateau pressure of less than $30 \mathrm{cmH}_{2} \mathrm{O}$.

\section{MAIN OUTCOME MEASURE}

Composite outcome of major respiratory complications, including pulmonary edema, respiratory failure, pneumonia, and re-intubation.

RESULTS

Of the 69265 enrolled patients 34800 (50.2\%) received protective ventilation and 34465 (49.8\%) received non-protective ventilation intraoperatively.

\section{WHAT IS ALREADY KNOWN ON THIS TOPIC}

Protective mechanical ventilation in patients with acute lung injury has gained widespread acceptance

It is unclear if patients with normal lungs undergoing brief intraoperative ventilation are vulnerable to ventilator induced lung injury

\section{WHAT THIS STUDY ADDS}

Protective ventilation reduces the risk of postoperative respiratory complications in a large group of patients undergoing a variety of surgical procedures

A positive end expiratory pressure (PEEP) of $5 \mathrm{cmH}_{2} \mathrm{O}$ and a plateau pressure of 16 $\mathrm{CmH}_{2} \mathrm{O}$ or less were identified as protective mechanical ventilator settings

Protective thresholds for intraoperative ventilation differ between patients with normal lungs and those with acute lung injury; a PEEP of $5 \mathrm{cmH}_{2} \mathrm{O}$ and a target plateau pressure selected as low as possible to reduce driving pressure and achieve adequate ventilation and oxygenation should be applied as a guideline when initiating intraoperative mechanical ventilation
Protective ventilation was associated with a decreased risk of postoperative respiratory complications in multivariable regression (adjusted odds ratio 0.90, $95 \%$ confidence interval 0.82 to $0.98, \mathrm{P}=0.013$ ). The results were similar in the propensity score matched cohort (odds ratio $0.89,95 \%$ confidence interval 0.83 to $0.97, \mathrm{P}=0.004)$. A PEEP of $5 \mathrm{cmH}_{2} \mathrm{O}$ and median plateau pressures of $16 \mathrm{cmH}_{2} \mathrm{O}$ or less were associated with the lowest risk of postoperative respiratory complications.

\section{CONCLUSIONS}

Intraoperative protective ventilation was associated with a decreased risk of postoperative respiratory complications. A PEEP of $5 \mathrm{~cm} \mathrm{H}_{2} \mathrm{O}$ and a plateau pressure of $16 \mathrm{cmH}_{2} \mathrm{O}$ or less were identified as protective mechanical ventilator settings. These findings suggest that protective thresholds differ for intraoperative ventilation in patients with normal lungs compared with those used for patients with acute lung injury.

\section{Introduction}

For decades it has been known that general anesthesia can impair oxygenation, even in patients with healthy lungs, ${ }^{12}$ and it is possible that the application of mechanical ventilation is a contributing factor. In patients with acute lung injury, invasive mechanical ventilation can lead to a progression of the disease rather than to recovery. A strategy of protective ventilation, consisting of low tidal volumes and plateau pressures and application of positive end expiratory pressure (PEEP) has gained widespread acceptance in intensive care units after large studies showed an associated reduction in morbidity and mortality in patients with acute lung injury. ${ }^{34}$ Information about the respiratory effects of mechanical ventilation in the operating room-where patients with normal lung function receive mechanical ventilation for a short period-is limited.

Postoperative respiratory complications represent the second most common perioperative complication after wound infection, ${ }^{56}$ with an estimated incidence ranging from $2.0 \%$ to $5.6 \%$ for surgical procedures. ${ }^{6-9}$ Respiratory failure after general anesthesia and tracheal extubation has been shown to be one of the most meaningful factors associated with poor patient outcomes, leading to longer hospital stays, ${ }^{61011}$ higher costs, ${ }^{56}$ and increased 30 day mortality. ${ }^{11} 12$

We assessed the effect of the intraoperative use of protective ventilation, as defined by published literature in perioperative medicine, ${ }^{413-15}$ on major 
postoperative respiratory complications. In a secondary analysis we assessed safe intraoperative mechanical ventilator settings, defined as the range of tidal volume, plateau pressure, and PEEP that do not translate into an increased risk of ventilator associated postoperative respiratory complications.

\section{Methods}

\section{Study design and setting}

We examined consecutive surgical patients who underwent general anesthesia between January 2007 and August 2014 at one tertiary care facility and two community hospitals in Massachusetts, United States.

\section{Patient selection}

Patients over the age of 18 who underwent a surgical procedure in an operating room and required general anesthesia and endotracheal intubation were included in the study. In the analysis we only considered patients who were extubated at the end of the procedure. Exclusion criteria were cardiac and thoracic procedures (since the opening of the chest cavity and single lung ventilation present unique perturbations to pulmonary physiology that we believe should be evaluated separately), surgical procedure within four weeks before the index operation, height less than $119 \mathrm{~cm}$ (calculations of predicted body weight become inaccurate at the extremes of size), ${ }^{16}$ and patients with missing data elements.

\section{Data source}

Data were obtained from the Anesthesia Information Management System, which was installed by the Department of Anesthesia, Critical Care and Pain Medicine at Massachusetts General Hospital in 2006. This system prospectively records intraoperative physiological data such as the applied PEEP, expiratory tidal volume and plateau pressures, systematically streaming from patient monitors and the anesthesia machine. Ventilator variables are recorded every minute. The system also contains information on medications administered intraoperatively, transfusions, airway management, and anesthetic technique. To collect additional preprocedural and post-procedural information, we used billing and demographic data from the research patient data registry, which is a centralized registry that compiles data from various institutional systems specifically for research purposes.

\section{Exposure}

Protective ventilation was defined a priori based on the previous literature in perioperative medicine. ${ }^{413-15}$ We classified patients as being ventilated protectively if they had a median applied PEEP of $5 \mathrm{cmH}_{2} \mathrm{O}$ or greater, a median expiratory tidal volume of less than $10 \mathrm{~mL} / \mathrm{kg}$ predicted body weight, and a median plateau pressure (obtained from a 10\% inspiratory pause during volume controlled ventilation, or the set pressure during pressure controlled ventilation) of less than $30 \mathrm{cmH}_{2} \mathrm{O}$. Patients had to meet each of these criteria to be placed in the protective ventilation group. We chose a tidal volume of less than $10 \mathrm{~mL} / \mathrm{kg}$ of predicted body weight on the basis of previous studies showing this as the injurious threshold ${ }^{1317}$ and on expert recommendations. ${ }^{18}$

\section{Covariate data}

Through the incorporation of data from the Anesthesia Information Management System and research patient data registry databases, we obtained data on the personal characteristics of our study population, including sex, age, height, body mass index, and American Society of Anesthesiologists physical status classification. To control for patient comorbidities, we used billing data to calculate the Charlson comorbidity index, as well as to identify patients with existing chronic pulmonary disease. ${ }^{19}$ For all patients we calculated the score for prediction of postoperative respiratory complications, which is a previously validated score used to determine a patient's risk of postoperative respiratory complications. $^{20}$

We controlled for surgical procedure by using current procedural terminology codes to first categorize abdominal procedures into four groups based on a previously published classification system: laparoscopic, major, minor or hernia repair, and retroperitoneal. ${ }^{21}$ The remaining sample was divided into the categories listed in table 1 using current procedural terminology codes and the listed surgical service. To adjust for surgical complexity we collected the work relative value units for each surgical operation within our sample. ${ }^{22}$ Current procedural terminology codes assigned a work relative value unit of zero are for procedure descriptions that are non-specific and were excluded from the dataset. ${ }^{23}$ We also obtained data related to a patient's individual procedure, such as duration of ventilation, use of epidural analgesia, transfusion of blood products, estimated blood loss, and whether the surgery was scheduled as emergent/urgent or ambulatory.

\section{Outcome measure}

We defined a composite outcome measure of major postoperative respiratory complications, which included re-intubation, respiratory failure, pneumonia, and pulmonary edema within three days of the procedure. These outcomes were defined using billing codes from the international statistical classification of diseases and related health problems, ninth revision (ICD-9) and current procedural terminology definitions. Supplementary table S1 provides a full list of the codes used to generate our outcome variables. The accuracy of these billing codes to define complications in the surgical population has been validated previously. $^{2425-27}$ Further, we have previously conducted a chart review to examine these codes in this database. ${ }^{2028}$ We excluded patients from the analysis with a billing code for any of the outcome variables on a date before their operation. Using previously published equations based on a patient's height and sex, we calculated predicted body weight. ${ }^{4}$ For men, predicted body weight was calculated as equal to 50+0.91(height (cm)-152.4) and for women it was calculated as 45.5+0.91(height (cm)-152.4). If a patient's height was 


\begin{tabular}{|c|c|c|c|}
\hline \multirow[b]{2}{*}{ Characteristics } & \multicolumn{2}{|l|}{ Ventilator type } & \multirow[b]{2}{*}{$\begin{array}{l}\text { Total } \\
(\mathrm{n}=69265)\end{array}$} \\
\hline & $\begin{array}{l}\text { Non-protective } \\
(\mathrm{n}=34 \text { 465) }\end{array}$ & $\begin{array}{l}\text { Protective }(n=34 \\
800)\end{array}$ & \\
\hline Men & $12246(35.5)$ & $18577(53.4)$ & $30823(44.5)$ \\
\hline \multicolumn{4}{|c|}{ American Society of Anesthesiologists classification: } \\
\hline 1 & 3351 (9.7) & 3157 (9.1) & $6508(9.4)$ \\
\hline 2 & $21006(61.0)$ & $21090(60.6)$ & $42096(60.8)$ \\
\hline 3 & $9664(28.0)$ & $10058(28.9)$ & $19722(28.5)$ \\
\hline 4 & $444(1.3)$ & $495(1.4)$ & $939(1.4)$ \\
\hline \multicolumn{4}{|l|}{ Surgery type: } \\
\hline Laparoscopic abdominal & $6892(20.0)$ & $5352(15.4)$ & $12244(17.7)$ \\
\hline Retroperitoneal & $1105(3.2)$ & $1324(3.8)$ & $2429(3.5)$ \\
\hline Hernia repair or minor abdominal & $1153(3.3)$ & $1116(3.2)$ & $2269(3.3)$ \\
\hline Major abdominal & $2647(7.7)$ & 3409 (9.8) & $6056(8.7)$ \\
\hline Hip and knee arthroplasty & $1441(4.2)$ & $2022(5.8)$ & $3463(5.0)$ \\
\hline Neurosurgery (non-spine) & $2499(7.3)$ & $2732(7.9)$ & $5231(7.6)$ \\
\hline Vascular & $1129(3.3)$ & $1746(5.0)$ & $2875(4.2)$ \\
\hline Plastic & $1316(3.8)$ & $1388(4.0)$ & $2704(3.9)$ \\
\hline Urologic (non-abdominal) & $2546(7.4)$ & $2889(8.3)$ & $5435(7.9)$ \\
\hline General (non-abdominal) & 3389 (9.8) & $2439(7.0)$ & $5828(8.4)$ \\
\hline Orthopedic (non-spine) & $5218(15.1)$ & $5853(16.8)$ & $11071(16.0)$ \\
\hline Spine & $1477(4.3)$ & $2161(6.2)$ & $3638(5.3)$ \\
\hline Breast & $2346(6.8)$ & $1435(4.1)$ & $3781(5.5)$ \\
\hline Gynecologic & $1307(3.8)$ & $934(2.7)$ & $2241(3.2)$ \\
\hline Epidural & $1976(5.7)$ & $2878(8.3)$ & $4854(7.0)$ \\
\hline Emergent/urgent & $3205(9.3)$ & $3647(10.5)$ & $6852(9.9)$ \\
\hline Ambulatory procedure & $7647(22.2)$ & $5366(15.4)$ & $13013(18.8)$ \\
\hline Existing chronic pulmonary disease & $4554(13.2)$ & $3912(11.2)$ & $8466(12.2)$ \\
\hline Mean (SD) units of packed cells transfused & $0.08(1.8)$ & $0.10(2.0)$ & $0.09(1.9)$ \\
\hline $\begin{array}{l}\text { Mean (SD) duration of intraoperative } \\
\text { ventilation (hours) }\end{array}$ & $2.8(2.4)$ & $3.1(2.6)$ & $2.9(2.5)$ \\
\hline Mean (SD) body mass index & $29.1(7.8)$ & $28.4(6.4)$ & $28.7(7.1)$ \\
\hline $\begin{array}{l}\text { Mean (SD) score for prediction of } \\
\text { postoperative respiratory complications* }\end{array}$ & $1.6(2.1)$ & $1.7(2.1)$ & $1.7(2.2)$ \\
\hline Mean (SD) age (years) & $54.1(16.6)$ & $55.2(16.1)$ & $54.7(16.4)$ \\
\hline Mean (SD) Charlson comorbidity indext & $2.1(2.9)$ & $2.2(3.0)$ & $2.2(2.9)$ \\
\hline Mean (SD) relative value units & $16.9(11.0)$ & $18.4(11.4)$ & $17.6(11.2)$ \\
\hline Mean (SD) total fluids administered (mL) & $2205.5(6463.6)$ & $2686.0(9204.5)$ & $2446.9(7963.1)$ \\
\hline Mean (SD) estimated blood loss (mL) & $145.5(324.4)$ & $196.4(381.4)$ & $171.0(355.1)$ \\
\hline Mean (SD) units of platelets transfused & $0.030(0.59)$ & $0.041(0.67)$ & $0.036(0.63)$ \\
\hline Mean (SD) units of fresh frozen plasma & $0.018(0.28)$ & $0.028(0.37)$ & $0.023(0.33)$ \\
\hline
\end{tabular}

missing from the anesthetic record, we obtained it through the research patient data registry.

\section{Statistical analysis}

For unadjusted analyses we used $\chi 2$ tests to determine the significance of associations between ventilator variables and the composite outcome. In the primary analysis we used multivariable logistic regression to ascertain the effect of protective ventilation on postoperative respiratory complications. Regression models were developed based on previously identified predictors of postoperative respiratory failure, ${ }^{20}$ predictors of non-protective ventilation, ${ }^{17} 2930$ and physiologic plausibility. Of the covariates, we treated units of packed cells, fresh frozen plasma, and platelets transfused, estimated blood loss in milliliters, age in years, duration of ventilation in hours, relative value units, body mass index, and Charlson comorbidity index as continuous variables and the remaining covariates as categorical or binary where appropriate.

To adjust for non-linear relations in continuous covariates we used the method of fractional polynomials. ${ }^{3132}$ We tested whether there was any indication of effect modification between protective ventilation and body mass index, score for prediction of postoperative respiratory complications, and duration. As none of the interaction terms indicated statistically significant effect modification (smallest $\mathrm{P}$ value 0.063 ), we proceeded without considering these interactions. As the regression models were built to evaluate a predefined exposure, we did not test colinearity between confounders and exposure.

To evaluate the robustness of the results, we created propensity score matched cohorts of patients. We used a logistic regression model with protective ventilation as the dependent variable and all of the covariates noted as independent variables. On the basis of the calculated propensity scores, we matched patients using a greedy algorithm without replacement that first identifies matched pairs (a treated person and an untreated person) within a closeness range of 0.00001 of the propensity score, then if no more individuals can be found, the program identifies matched pairs in a range of 0.0001 , and so on up to a closeness range of $0.1 .^{33}$ Using the propensity score as a covariate in a regression outcome model in the entire study cohort resulted in similar effect estimates, indicating no differential effects among patients who could not be matched. ${ }^{34}$

Our two community hospitals were ambulatory care centers and we did not observe respiratory complications after ambulatory surgery in these patients. Thus we pooled data from all three centers in the analyses. To evaluate whether there was residual confounding due to differences between hospitals, we included information on the hospitals in the propensity score model. As no change in the final effect estimate was observed, we continued with a propensity score model not including this variable. All other variables were included in the regression model without further selection but based on a priori consideration.

Our secondary analysis focused on further characterizing the individual effects of plateau pressure, tidal volume, PEEP, and driving pressure (plateau pressure minus PEEP) using regression models. We sought to define safe intraoperative mechanical ventilator settings-that is, the range of tidal volume, plateau pressure, and PEEP that do not translate into an increased risk of ventilator associated postoperative respiratory complications. To evaluate this dose-response relation we divided our sample into fourths based on median tidal volume, plateau pressure, and driving pressure, and we performed a separate regression analysis for each of these measures. We performed a similar procedure for PEEP. However, given that nearly half of the patients had a PEEP value of $5 \mathrm{cmH}_{2} \mathrm{O}$, we were unable to create four equal groups and so the sample was divided into thirds. We used a separate logistic regres- 
sion model for each variable-that is, PEEP, tidal volume, and plateau pressure.

\section{Sensitivity analyses}

To investigate the impact of variation by individual providers on the primary result we accounted for clustering of patients by provider. Individual providers were defined as the primary anesthesia provider listed in the anesthetic record and could be a resident physician, certified nurse anesthetist, or staff anesthesiologist. We used a mixed effects logistic regression model, with protective ventilation as the dependent variable and the covariates used in the primary analysis as fixed effects. Individual providers were added to the model as a random effect.

For the initial analysis we used the complete case method to deal with missing data. Given the considerable number of patients with missing data, we repeated the primary analysis using multiple imputation by chained equations. ${ }^{35}$ Missing variables were imputed using all variables included in the main analysis, as well as the outcome variable. Further, we examined whether the effect estimate remained the same when patients from the ambulatory centers were removed from the cohort. Additional covariates that were not initially included in the model were considered as part of sensitivity analyses and included the total dosage of propofol in milligrams, the median minimum alveolar concentration of volatile anesthetic, and the amount of colloids received in milliliters. To assess for bias related to a possible change in clinical practice over time, we incorporated year of procedure into the model and re-ran the primary analysis.

We also performed additional analyses using several other outcomes to determine the robustness of our results. Prolonged length of stay was examined and defined as a length of stay of greater than the 90th centile or eight days. We obtained data on 30 day in-hospital mortality. Given the few number of events, however, the model did not reach convergence when we used multivariable logistic regression in the entire cohort. Thus we calculated an unadjusted odds ratio using the propensity score matched cohort to determine the association between mortality and protective ventilation. We also investigated the outcomes of renal failure and wound dehiscence since these would not be expected to be associated with protective ventilation. All covariates used in the primary analysis were included in these regression models.

To further accommodate for potential differential effects of pre-existing restrictive disease of the respiratory system on the association between plateau pressure and postoperative respiratory complications, we incorporated compliance (median tidal volume divided by the median plateau pressure subtracted from the median PEEP) as an additional analysis. We also concurrently adjusted for tidal volume as an additional sensitivity analysis to further evaluate the impact of plateau pressure. Further, we performed a subgroup analysis of patients who received pressure control ventilation.
Statistical tests were two tailed and we considered a $P$ value of less than 0.05 to be significant. All analyses were performed in Stata (version 12; StataCorp, College Station, TX), with the exception of propensity score matching, which was performed in SAS (version 9.3; SAS, Carey, NC).

\section{Results}

\section{Primary analysis}

Overall, 91945 patients underwent anesthesia during the study time period, of whom 69265 met the eligibility criteria (fig 1). Supplementary table S2 describes the cohort with missing data. A total of 34800 (50.2\%) patients received protective intraoperative ventilation and 34465 (49.8\%) non-protective intraoperative ventilation. Table 1 provides details of the patients' personal and surgical characteristics. Unimodal and broad distributions of tidal volume and plateau pressure and a bimodal distribution of positive end expiratory pressure (PEEP) were observed (fig 2) (supplementary table S3 shows the ventilation variables for the two groups). In unadjusted analyses a positive association was found between the use of protective ventilation and the development of postoperative pulmonary complications $(\mathrm{P}=0.025)$. (Supplementary table S4 shows the results for unadjusted analyses.) Using multivariable logistic regression analysis, patients who were ventilated with a protective strategy were significantly less likely to experience a postoperative respiratory complication (odds ratio $0.90,95 \%$ confidence interval 0.82 to $0.98, \mathrm{P}=0.013$ ). When using propensity score matching, 4105 patients could not be matched, leaving a matched cohort of 65160 patients. Table 2 provides the characteristics of the matched cohort. In unconditional logistic regression analysis of this cohort, the odds ratio associated with protective ventilation was similar to that of the unmatched cohort $(0.89,95 \%$ confidence interval 0.83 to $0.97, \mathrm{P}=0.004)$.

\section{Secondary analysis}

We employed separate regression models to determine the individual effects of plateau pressure, tidal volume, and PEEP. Predefined levels of plateau pressure (odds ratio $0.66,95 \%$ confidence interval 0.53 to $0.81, \mathrm{P}<0.001$ ) and PEEP (0.91, 0.83 to $0.99, \mathrm{P}=0.037$ ) were associated

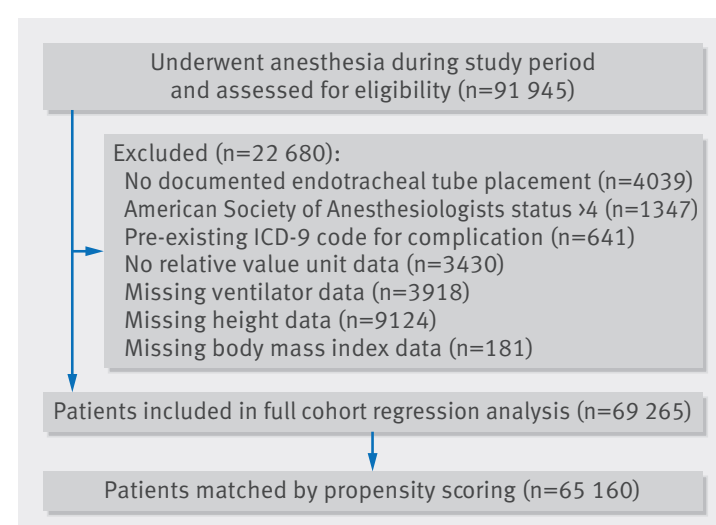

Fig 1 | Flow of patients through study 

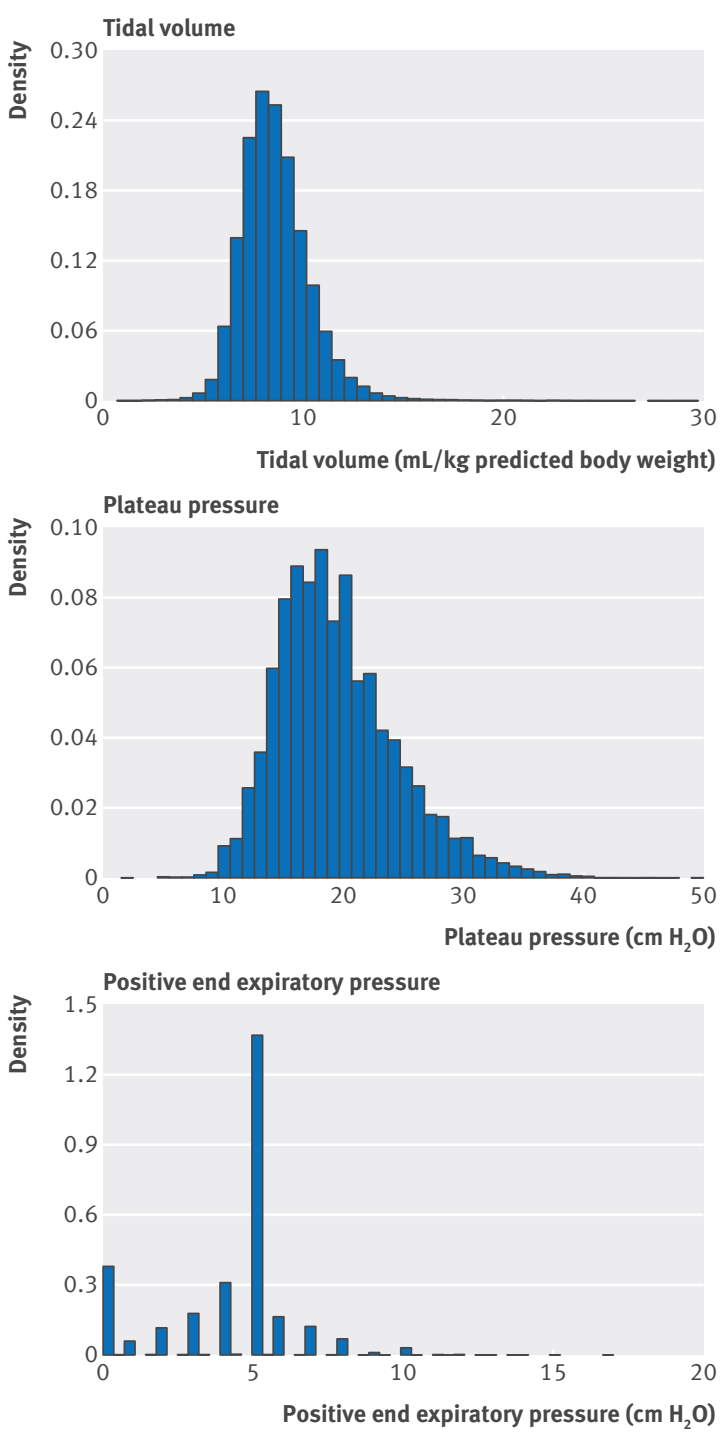

Fig 2 Distributions of median positive end expiratory pressure (PEEP), tidal volume, and plateau pressure in full unmatched cohort

with a decreased risk of ventilator induced postoperative respiratory complications. A tidal volume of less than $10 \mathrm{~mL} / \mathrm{kg}$ of predicted body weight was not associated with a significant decrease in complications (0.94, 0.82 to $1.05, \mathrm{P}=0.23$ ). Similar results were obtained when the same analysis was performed in the matched cohort (table 3). When all three components were included in the same regression model, a low plateau pressure $(0.66,0.53$ to $0.81, \mathrm{P}<0.001)$ and PEEP $(0.91,0.83$ to 0.99 , $\mathrm{P}=0.034)$ were protective, whereas a low tidal volume was not associated with complications $(0.94,0.83$ to 1.07, $\mathrm{P}=0.35)$.

Plateau pressure was associated with an increasing risk of respiratory complications in a dose dependent manner (fig 3). A median plateau pressure of less than $16 \mathrm{cmH}_{2} \mathrm{O}$ was identified as a protective ventilator setting, with no increased risk in ventilator associated postoperative respiratory complications. A higher driving pressure was associated with an increased risk of postoperative pulmonary complications, with a similar effect magnitude (see supplementary figure S1). When different levels of PEEP were examined, the middle third, which corresponded to a PEEP of $5 \mathrm{cmH}_{2} \mathrm{O}$, had less risk than the lowest third-that is, a PEEP less than $5 \mathrm{cmH}_{2} \mathrm{O}$ (odds ratio $0.89,95 \%$ confidence interval 0.80 to $0.98, \mathrm{P}=0.013$, (see fig 3 ). In our collective of patients without acute lung injury, tidal volume did not have a significant impact on postoperative respiratory complications across fourths (fig 3).

\section{Sensitivity analyses}

Within the entire unmatched cohort there were 655 anesthesia providers. A total of 1132 patients (1.6\%) did not have an anesthesia provider listed and were excluded from this sensitivity analysis. When anesthesia provider was included as a random effect in a mixed effects regression model, the estimate of the impact of protective ventilation was unchanged from the primary analysis (odds ratio 0.87, 95\% confidence interval 0.81 to $0.96, \mathrm{P}=0.004)$. Incorporating the year of surgical procedure did not affect the results (0.90, 0.83 to 0.99 , $\mathrm{P}=0.022)$, nor did the imputation of missing data ( 0.84 , 0.78 to $0.91, \mathrm{P}<0.001)$. When we excluded ambulatory care centers, protective ventilation remained associated with postoperative respiratory complications (0.89, 0.82 to $0.97, \mathrm{P}=0.012$ ). Finally, incorporating additional potential confounders, including the amount of colloids, propofol dosage, median minimum alveolar concentration, and total morphine equivalents did not change the result $(0.90,0.83$ to $0.99, \mathrm{P}=0.022)$.

To further minimize the bias of pre-existing respiratory disease we added compliance to the regression model. This addition did not affect the identification of plateau pressure as a significant predictor of postoperative respiratory complications (see supplementary figure S2). We also examined the relation of tidal volume and respiratory complications while adjusting for compliance and found that the tidal volume remained non-significant (see supplementary figure S3). To determine whether the impact of plateau pressure was attributed to tidal volume, we performed an additional regression adjusting for tidal volume and plateau pressure concurrently. The results showed that a higher plateau pressure was still associated with increased rates of respiratory complications (see supplementary figure S4). In the subset of patients ventilated with pressure control $(n=9035)$, a similar association between plateau pressure and postoperative respiratory complications was observed (see supplementary figure S5).

Data on length of stay were available for 53454 patients. In this subset of the full cohort we observed a reduced risk of prolonged length of stay for patients who received protective ventilation (odds ratio 0.94, 95\% confidence interval 0.87 to $1.01, \mathrm{P}=0.09$ ), which was marginally significant. No significant association was found between 30 day in-hospital mortality and protective ventilation $(0.98,0.80$ to $1.19, \mathrm{P}=0.81)$. Protective ventilation was not found to be associated with renal failure $(0.95,0.80$ to $1.12, \mathrm{P}=0.53)$ or wound dehiscence (0.99, 0.80 to $1.23, \mathrm{P}=0.94)$. 


\begin{tabular}{|c|c|c|c|}
\hline \multirow[b]{2}{*}{ Characteristics } & \multicolumn{2}{|l|}{ Ventilator type } & \multirow[b]{2}{*}{$\begin{array}{l}\text { Total } \\
(\mathrm{n}=65160)\end{array}$} \\
\hline & $\begin{array}{l}\text { Non-protective } \\
(\mathrm{n}=32580)\end{array}$ & $\begin{array}{l}\text { Protective } \\
(n=32580)\end{array}$ & \\
\hline Men & $16382(50.3)$ & $16369(50.2)$ & $32751(50.3)$ \\
\hline \multicolumn{4}{|c|}{ American Society of Anesthesiologists classification: } \\
\hline 1 & $3068(9.4)$ & $3039(9.3)$ & $6107(9.4)$ \\
\hline 2 & $19700(60.5)$ & $19751(60.6)$ & $39451(60.5)$ \\
\hline 3 & $9352(28.7)$ & $9339(28.7)$ & $18691(28.7)$ \\
\hline 4 & $460(1.4)$ & $451(1.4)$ & $911(1.4)$ \\
\hline \multicolumn{4}{|l|}{ Surgery type: } \\
\hline Laparoscopic abdominal & $5119(15.7)$ & $5288(16.2)$ & $10407(16.0)$ \\
\hline Retroperitoneal & $1201(3.7)$ & $1216(3.7)$ & $2417(3.7)$ \\
\hline Hernia repair or minor abdominal & $1095(3.4)$ & $1087(3.3)$ & $2182(3.4)$ \\
\hline Major abdominal & 2969 (9.1) & $3032(9.3)$ & $6001(9.2)$ \\
\hline Hip and knee arthroplasty & $1648(5.1)$ & $1710(5.3)$ & $3358(5.2)$ \\
\hline Neurosurgery (non-spine) & $2700(8.3)$ & $2596(8.0)$ & $5296(8.1)$ \\
\hline Vascular & $1443(4.4)$ & $1430(4.4)$ & $2873(4.4)$ \\
\hline Plastic & $1338(4.1)$ & $1314(4.0)$ & $2652(4.1)$ \\
\hline Urologic (non-abdominal) & $2898(8.9)$ & $2784(8.6)$ & $5682(8.7)$ \\
\hline General (non-abdominal) & $2461(7.6)$ & $2436(7.5)$ & $4897(7.5)$ \\
\hline Orthopedic (non-spine) & $5481(16.8)$ & $5471(16.8)$ & $10952(16.8)$ \\
\hline Spine & $1834(5.6)$ & $1847(5.7)$ & $3681(5.7)$ \\
\hline Breast & $1434(4.4)$ & $1435(4.4)$ & $2869(4.4)$ \\
\hline Gynecologic & $959(2.9)$ & $934(2.9)$ & $1893(2.9)$ \\
\hline Epidural & 2366 (7.3) & $2424(7.4)$ & $4790(7.4)$ \\
\hline Emergent/urgent & $3286(10.1)$ & $3345(10.3)$ & $6631(10.2)$ \\
\hline Ambulatory procedure & $5451(16.7)$ & $5360(16.5)$ & $10811(16.6)$ \\
\hline Existing chronic pulmonary disease & $3760(11.5)$ & $3784(11.6)$ & $7544(11.6)$ \\
\hline $\begin{array}{l}\text { Mean (SD) units of packed cells } \\
\text { transfused }\end{array}$ & $0.08(0.45)$ & $0.09(2.0)$ & $0.09(1.5)$ \\
\hline $\begin{array}{l}\text { Mean (SD) duration of intraoperative } \\
\text { ventilation (hours) }\end{array}$ & $3.0(2.6)$ & $3.0(2.5)$ & $3.0(2.5)$ \\
\hline Mean (SD) body mass index & $28.3(6.9)$ & $28.5(6.5)$ & $28.4(6.7)$ \\
\hline $\begin{array}{l}\text { Mean (SD) score for prediction of } \\
\text { postoperative respiratory } \\
\text { complications }^{\star}\end{array}$ & $1.7(2.1)$ & $1.7(2.1)$ & $1.7(2.1)$ \\
\hline Mean (SD) age (years) & $55.1(16.7)$ & $55.0(16.1)$ & $55.03(16.4)$ \\
\hline Mean (SD) Charlson comorbidity indext & $2.2(3.0)$ & $2.2(2.9)$ & $2.2(2.9)$ \\
\hline Mean (SD) relative value units & $18.1(11.6)$ & $18.0(11.3)$ & $18.03(11.4)$ \\
\hline $\begin{array}{l}\text { Mean (SD) total fluids } \\
\text { administered }(\mathrm{mL})\end{array}$ & $2403.6(6758.3)$ & $2456.0(7770.8)$ & $2429.8(7282.2)$ \\
\hline
\end{tabular}

administered $(\mathrm{mL})$

\begin{tabular}{llll}
\hline Mean (SD) estimated blood loss (mL) & $173.1(338.6)$ & $176.9(327.3)$ & $175.0(333.0)$ \\
\hline Mean (SD) units of platelets transfused & $0.036(0.66)$ & $0.036(0.61)$ & $0.036(0.64)$ \\
\hline Mean (SD) units of fresh frozen plasma & $0.022(0.29)$ & $0.023(0.31)$ & $0.023(0.30)$ \\
\hline
\end{tabular}

*Previously validated 11 point score; each point increment is associated with a 1.7-fold (odds ratio 1.72, 95\% confidence interval 1.55 to 1.91 ) increase in the odds for reintubation. ${ }^{20}$

tSummary measure of patient's burden of disease based on international classification of diseases codes. ${ }^{19}$

Table 3 Adjusted analysis determining the impact of protective ventilation on postoperative respiratory complications

\begin{tabular}{|c|c|c|c|c|}
\hline \multirow[b]{2}{*}{ Exposure } & \multicolumn{2}{|c|}{$\begin{array}{l}\text { Entire unmatched cohort with } \\
\text { logistic regression* }(n=69265)\end{array}$} & \multicolumn{2}{|c|}{$\begin{array}{l}\text { Propensity matched cohort } \\
(\mathrm{n}=65160)\end{array}$} \\
\hline & Odds ratio $(95 \% \mathrm{Cl})$ & Pvalue & Odds ratio $(95 \% \mathrm{Cl})$ & $P$ value \\
\hline Protective ventilation & 0.90 (0.82 to 0.98$)$ & 0.013 & 0.89 (0.83 to 0.97 ) & 0.004 \\
\hline PEEP $\geq 5 \mathrm{~cm} \mathrm{H}_{2} \mathrm{O}$ & 0.91 (0.83 to 0.99$)$ & 0.037 & 0.89 (0.82 to 0.96$)$ & 0.004 \\
\hline Plateau pressure $<30 \mathrm{cml}$ & $0.66(0.53$ to 0.81$)$ & $<0.001$ & $0.71(0.59$ to 0.86$)$ & $<0.001$ \\
\hline Tidal volume $<10 \mathrm{~mL} / \mathrm{kg}$ of & $0.94(0.82$ to 1.05$)$ & 0.23 & $1.12(0.99$ to 1.25$)$ & 0.056 \\
\hline
\end{tabular}

predicted body weight

PEEP=positive end expiratory pressure.

*Each row represents a separate regression model adjusting for patient body mass index, age, sex, American Society of Anesthesiologists classification, score for prediction of postoperative respiratory complications (each point increment is associated with a 1.7 -fold (odds ratio $1.72,95 \%$ confidence interval 1.55 to 1.91 ) increase in the odds for reintubation), Charlson comorbidity index, work relative value units, pre-existing chronic pulmonary disease, surgery type, duration of ventilation, epidural placement, units of packed red blood cells, fresh frozen plasma and platelets transfused, ambulatory surgery, urgent/emergent surgery, estimated blood loss, and total fluids administered.

\section{Discussion}

Our data show that utilizing a protective ventilation strategy intraoperatively is associated with a significantly lower risk of major postoperative respiratory complications in a large cohort of patients undergoing a variety of non-cardiac surgical procedures. A positive end expiratory pressure (PEEP) of $5 \mathrm{cmH}_{2} \mathrm{O}$ and a plateau pressure of $16 \mathrm{cmH}_{2} \mathrm{O}$ or less were identified as protective mechanical ventilator targets that did not result in an increased risk of ventilator associated postoperative respiratory complications.

\section{Comparison with other studies}

This study supports the view that protective intraoperative ventilation strategies improve postoperative respiratory outcomes in a broad population of patients. Whereas protective ventilation is well established for the management of acute respiratory distress syndrome, there is still controversy on the impact of mechanical intraoperative ventilation on outcomes in patients without acute lung injury. ${ }^{1336}$ A randomized trial on 400 intermediate-high risk patients undergoing major abdominal surgery reported a decreased risk of a composite of pulmonary and extrapulmonary complications in patients receiving protective ventilation (tidal volume 6-8 mL/ kg, PEEP 6-8 $\mathrm{cm} \mathrm{H}_{2} \mathrm{O}$, and recruitment maneuvers repeated every 30 minutes) compared with non-protective ventilation (tidal volume $10-12 \mathrm{~mL} / \mathrm{kg}$, with no PEEP and no recruitment maneuvers). ${ }^{13} \mathrm{~A}$ small randomized trial of patients undergoing open abdominal surgery lasting more than two hours found that those ventilated protectively (tidal volume $7 \mathrm{~mL} / \mathrm{kg}$, PEEP $10 \mathrm{cmH}_{2} \mathrm{O}$, and recruitment maneuvers) had improved pulmonary function tests, fewer alterations in chest radiographs, and higher postoperative arterial oxygen saturation. ${ }^{14}$ A large meta-analysis based on these data obtained from patients without acute respiratory distress syndrome and ventilated in operating room showed a lower odds for postoperative pulmonary complications in those receiving lower tidal volumes. ${ }^{37}$ Our analysis indicates that the benefits of protective intraoperative ventilation strategies apply to a large group of intraoperative patients undergoing a variety of surgical procedures and are not restricted to high risk patients and abdominal surgery.

Our secondary analysis showed that both no PEEP and higher plateau pressures were associated with respiratory complications. The protective ventilator settings observed in this trial differ from the tidal volumes and plateau pressures recommended for mechanical ventilation of patients with acute respiratory distress syndrome. High tidal volumes were not associated with an increased risk of postoperative respiratory complications.

We observed an association between reduction in plateau pressure and a decrease in major postoperative pulmonary complications down to a median plateau pressure of $16 \mathrm{cmH}_{2} \mathrm{O}$. This suggests that thresholds of plateau pressure often mentioned as "safe" (for example, 26-30 $\mathrm{cmH}_{2} \mathrm{O}$ ) cannot be applied as a justification not to make attempts to use the lowest possible plateau 


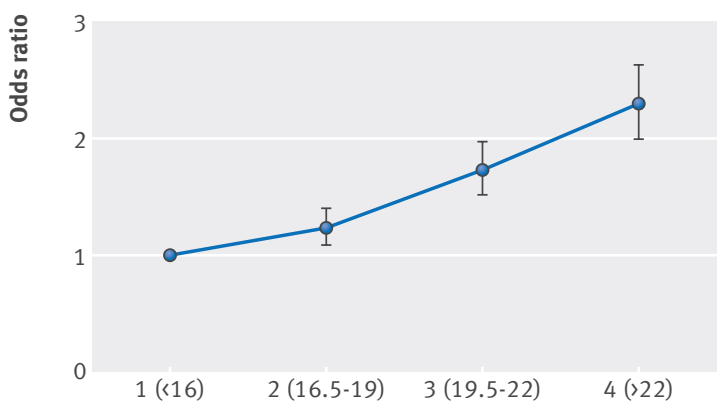

Plateau pressure fourth (associated range, $\mathrm{cm} \mathrm{H}_{2} \mathrm{O}$ )

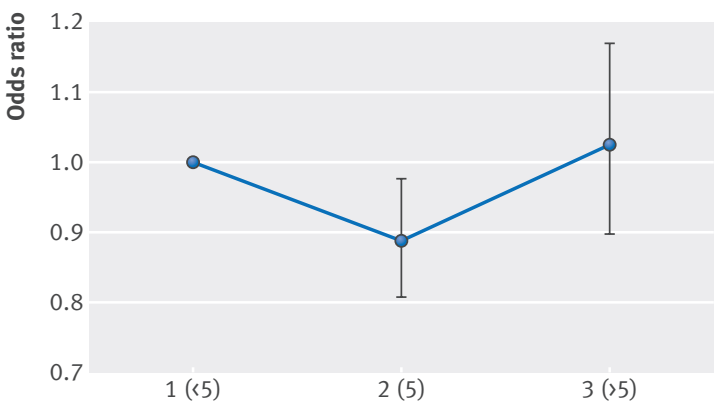

Positive end expiratory pressure third (associated range, $\mathrm{cm} \mathrm{H}_{2} \mathrm{O}$ )

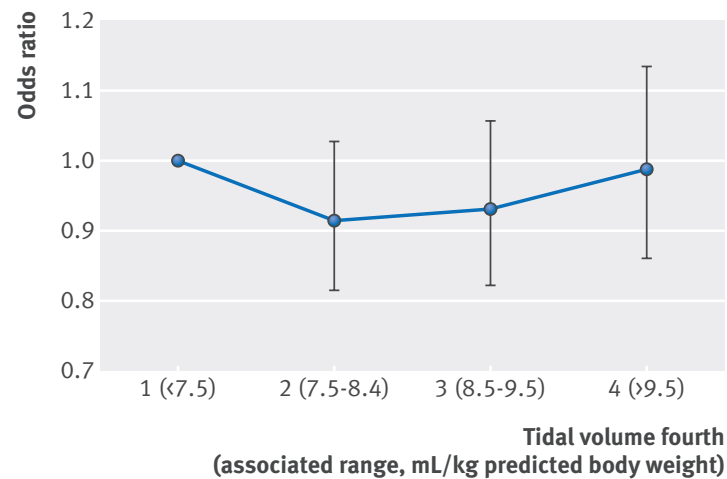

Fig 3 | Multivariable logistic regression analysis examining the impact of plateau pressure, positive end expiratory pressure (PEEP), and tidal volume on postoperative pulmonary complications in entire unmatched cohort. Each graph represents a separate regression model adjusting for body mass index, age, sex, American Society of Anesthesiologists classification, score for prediction of postoperative respiratory complications, Charlson comorbidity index, work relative value units, pre-existing chronic pulmonary disease, surgery type, duration of ventilation, epidural placement, units of packed red blood cells, fresh frozen plasma and platelets transfused, ambulatory surgery, urgent/emergent surgery, estimated blood loss, and total fluids administered

pressure for protective ventilation in surgical patients without acute lung injury.

Plateau pressures are a function of the applied PEEP and the ratio between a patient's tidal volume and compliance. The effect of high plateau pressures and driving pressures (plateau pressure minus PEEP) in increasing postoperative respiratory complication were similar. Our sensitivity analysis indicated that the increased vulnerability to postoperative respiratory complications with high plateau pressures and high driving pressures is not due to the independent effects of compliance and tidal volume. Thus, we infer based on our data that it is the interplay between tidal volume and compliance (that is, the tidal volume to compliance ratio) that determines the observed pathogenic effects of high plateau pressure and high driving pressure on outcomes. This ratio is associated with cyclic lung strain and our results show that in surgical patients it relates better to outcomes than to tidal volumes, in line with recent observations in patients with acute respiratory distress syndrome. ${ }^{38}$ Higher tidal volumes in the presence of lower compliances should increase the risk for postoperative respiratory complications. Importantly, both of these factors are modifiable intraoperatively since plateau pressure depends on ventilator settings and compliance may be increased when additional lung tissue is recruited by PEEP or a recruitment maneuver. Transpulmonary pressure (airway pressure minus pleural pressure) is the component of the plateau pressure that reflects the magnitude of stress applied to the lungs during mechanical ventilation. Larger plateau pressures could result in larger injurious lung stress even at pressures below $30 \mathrm{cmH}_{2} \mathrm{O}$ in patients with normal pulmonary compliance.

The analysis also showed that a PEEP of $5 \mathrm{cmH}_{2} \mathrm{O}$ seemed to be beneficial when compared with lower or higher values. In a randomized trial of high $\left(12 \mathrm{cmH}_{2} \mathrm{O}\right)$ versus low $\left(\leq 2 \mathrm{cmH}_{2} \mathrm{O}\right)$ PEEP in 900 patients undergoing open abdominal surgery, pulmonary complications did not differ between the two groups. ${ }^{39}$ The discrepancy between our results and this trial could be because there may be an optimal level of PEEP that protects against intraoperative low volume lung injury. Future studies are required to define the role of intraoperative PEEP in the development of postoperative respiratory complications within subgroups of patients defined by surgical procedure and compliance of the respiratory system. ${ }^{40}$

We decided before the initiation of the analysis to use a tidal volume cut-off of $10 \mathrm{~mL} / \mathrm{kg}$ of predicted body weight for the definition of protective ventilation. In mechanically ventilated patients in the intensive care unit, it has been shown that adoption of a strategy of limited tidal volumes in all patients to values lower than $10 \mathrm{~mL} / \mathrm{kg}$ predicted body weight resulted in a lower incidence of acute respiratory distress syndrome and higher survival. ${ }^{41}$ Experts who reviewed this subject have previously recommended a tidal volume of less than $10 \mathrm{~mL} / \mathrm{kg}$ and a PEEP of $5 \mathrm{cmH}_{2} \mathrm{O}$ for patients with healthy lungs. ${ }^{42}$ In our cohort of patients without acute lung injury, tidal volume in the range studied did not have an important impact on postoperative respiratory complications.

A definition of protective ventilation that captures all patients across disease entities and surgical procedures does not exist. Based on the different mechanisms producing ventilator induced lung injury (for example, lung over-distension, concentration of mechanical forces, propagation of liquid-gas interfaces, cyclic recruitment of small airways and alveoli, associated 
biotrauma) and the variability of disease in humans, each patient will require an individualized form of "protective" ventilation. Tissue strain (defined as change in lung volume divided by initial volume) is a key variable at the tissue level to which several of those mechanisms of ventilator induced lung injury converge. ${ }^{43}$ Because on average the functional residual capacity of surgical patients is substantially higher than that of patients with acute respiratory distress syndrome, strains in surgical patients will be lower than those in patients with acute respiratory distress syndrome for similar tidal volumes. Our data indicating the absence of an independent effect of higher tidal volumes on pulmonary complications for surgical patients is consistent with this pathophysiological consideration.

\section{Strengths and limitations of this study}

The data analyzed were from a tertiary care academic center and two affiliated community hospitals. Thus our sample included a diverse group of patients, practitioners, and procedures and the findings are likely to be relevant to an equally diverse range of settings. Our large sample with a sufficient number of outcome events allowed for a detailed analysis of the dose-response relation of protective ventilation that would be difficult to accomplish with a randomized controlled trial.

The study does have limitations. Outcomes were based on administrative data, and misclassification is possible. However, physicians entering billing diagnoses access the paper record, which does not give information on ventilation patterns as described in our study. Thus we have no reason to suspect that there was a differential in the reporting of respiratory complications for type of ventilation received intraoperatively. We also conducted sensitivity analyses using several additional outcomes. Results indicated that protective ventilation was associated with a lower likelihood of prolonged length of stay, but this result did not reach formal statistical significance. We also included outcomes that we would not expect to be associated with protective ventilation such as wound dehiscence and found that these were indeed not related to our exposure. All of these results together reassure us that our end point of postoperative respiratory complication as well as its association with protective ventilation in the operating room was clinically meaningful.

The study was observational in nature and thus we cannot exclude influences of unmeasured confounding. For example, the anesthesia information management system did not capture the use of recruitment maneuvers, which could have been more prevalent in patients who were ventilated protectively. However, we were able to correct for important confounders, and the results of our study imply a negative confounding effect-that is, an underestimation of the effects of protective ventilation can occur from the lack of confounder adjustment. Furthermore, the results of the analysis remained robust with different analytical approaches.
Finally we only examined patients who were extubated at the conclusion of the procedure. If we had extended the analysis to patients who remained intubated at the conclusion of surgery, we would have had to account for numerous postoperative factors, such as the mechanical ventilator settings in the intensive care unit, to isolate the effect of intraoperative mechanical ventilation. This was not possible with the dataset. Excluding these patients may, however, have biased our results towards the null since non-protective ventilation could lead to respiratory complications and result in a decision to keep patients intubated.

\section{Conclusions and policy implications}

The results of our study provide strong evidence that intraoperative ventilation strategies have an impact on postoperative respiratory complications. Based on our findings, a PEEP of $5 \mathrm{cmH}_{2} \mathrm{O}$ and a target plateau pressure selected as low as reasonably possible to reduce driving pressure and achieve adequate ventilation and oxygenation should be applied as a guideline when initiating intraoperative mechanical ventilation. The thresholds discovered in our analysis differ from those used in patients with acute lung injury suggesting that clinicians should use different ventilator settings in patients with and without pulmonary disease. These new results can help select ventilator settings for most patients receiving mechanical ventilation during a surgical procedure.

We thank Jeff and Judy Buzen for their generous support of this study, and the staff of the Perioperative Clinical Engineering \& Anesthesia IT Systems team at Massachusetts General Hospital for supporting data acquisition from the electronic anesthesia record.

Contributors: KL contributed to the design and conception of the study, the analysis and interpretation of data, and drafting of the work. MFVM contributed to the design and conception of the study. DJMCL contributed to the design and conception of the work, as well as to the acquisition of data. JPW and SDG contributed to the acquisition of data for the work. TK contributed to design and conception of the study, to the data analysis and interpretation of data. ME is the guarantor of the paper. He takes responsibility for the integrity of the work as a whole, from inception to published article. All authors revised the work critically for important intellectual content. TK and ME made equal contributions and served as epidemiological and clinical research mentors to $\mathrm{KL}$, respectively.

Funding: This study was funded by a grant from the Buzen's Foundation.

Competing interests: All authors have completed the ICMJE uniform disclosure form at www.icmje.org/coi_disclosure.pdf and declare: no support from any organisation for the submitted work; MFVM has within the last two years received funding from the US National Institutes of Health (grant 1R01HL121228-01) and investigator initiated funding from Merck. TK has within the past two years received investigator initiated research funding from the French National Research Agency and the US National Institutes of Health. Further, he has received honorariums from the BMJ and Cephalalgia for editorial services. JPW is supported by a mentored research training grant in health services research from the Foundation for Anesthesia Education and Research and the Anesthesia Quality Institute. ME has within the past two years received investigator initiated research funding from Masimo, Merck, the ResMed Foundation, and the Buzen's Foundation. Further, he has received honorariums from Anesthesiology for editorial services. There are no other relationships or activities that could appear to have influenced the submitted work.

Ethical approval: This project was approved by the Partners institutional review board (protocol No 2013P001954).

Data sharing: No additional data available.

Transparency: The guarantor (ME) affirms that the manuscript is an honest, accurate, and transparent account of the study being reported; 
that no important aspects of the study have been omitted; and that any discrepancies from the study as planned (and, if relevant, registered) have been explained

This is an Open Access article distributed in accordance with the Creative Commons Attribution Non Commercial (CC BY-NC 4.0) license, which permits others to distribute, remix, adapt, build upon this work non-commercially, and license their derivative works on different terms, provided the original work is properly cited and the use is non-commercial. See: http://creativecommons.org/licenses/ by-nc/4.0/.

1 Nunn JF, Payne JP. Hypoxaemia after general anaesthesia. Lancet $1962 ; 2: 631-2$

2 Bendixen HH, Hedley-Whyte J, Laver MB. Impaired oxygenation in surgical patients during general anesthesia with controlled ventilation. A concept of atelectasis. N Engl I Med 1963;269:991-6.

3 Amato MB, Barbas CS, Medeiros DM, Magaldi RB, Schettino GP, Lorenzi-Filho G, et al. Effect of a protective-ventilation strategy on mortality in the acute respiratory distress syndrome. N Engl / Med 1998;338:347-54

4 Acute Respiratory Distress Syndrome Network. Ventilation with lowe tidal volumes as compared with traditional tidal volumes for acute lung injury and the acute respiratory distress syndrome. N Engl / Med 2000;342:1301-8

5 Dimick JB, Chen SL, Taheri PA, Henderson WG, Khuri SF, Campbell DA Hospital costs associated with surgical complications: a report from the private-sector National Surgical Quality Improvement Program. J Am Coll Surg 2004;199:531-7.

6 Khuri SF, Henderson WG, DePalma RG, Mosca C, Healey NA, Kumbhani DJ, et al. Determinants of long-term survival after major surgery and the adverse effect of postoperative complications. Ann Surg 2005;242:323-6.

7 Johnson RG, Arozullah AM, Neumayer L, Henderson WG, Hosokawa P, Khuri SF. Multivariable predictors of postoperative respiratory failure after general and vascular surgery: results from the patient safety in surgery study. I Am Coll Surg 2007;204:1188-98.

8 Arozullah AM, Daley J, Henderson WG, Khuri SF. Multifactorial risk index for predicting postoperative respiratory failure in men after major noncardiac surgery. The National Veterans Administration Surgical Quality Improvement Program. Ann Surg 2000;232:242-53.

9 Canver CC, Chanda J. Intraoperative and postoperative risk factors for respiratory failure after coronary bypass. Ann Thorac Surg 2003;75:853-8.

10 Smetana GW. Postoperative pulmonary complications: an update on risk assessment and reduction. Cleve Clin J Med 2009;76(Suppl 4):S60-5.

11 Nafiu OO, Ramachandran SK, Ackwerh R, Tremper KK, Campbell DA, Stanley JC. Factors associated with and consequences of unplanned post-operative intubation in elderly vascular and general surgery patients. Eur I Anaesthesiol 2011;28:220-4.

12 Ramachandran SK, Nafiu 00, Ghaferi A, Tremper KK, Shanks A, Kheterpal S. Independent predictors and outcomes of unanticipated early postoperative tracheal intubation after nonemergent, noncardiac surgery. Anesthesiology 2011;115:44-53.

13 Futier E, Constantin J-M, Paugam-Burtz C, Pascal J, Eurin M, Neuschwander A, et al. A trial of intraoperative low-tidal-volume ventilation in abdominal surgery. N Engl / Med 2013;369:428-37.

14 Severgnini P, Selmo G, Lanza C, Chiesa A, Frigerio A, Bacuzzi A, et al. Protective mechanical ventilation during general anesthesia for open abdominal surgery improves postoperative pulmonary function. Anesthesiology 2013;118:1307-21.

15 Treschan TA, Kaisers W, Schaefer MS, Bastin B, Schmalz U, Wania V, et al. Ventilation with low tidal volumes during upper abdominal surgery does not improve postoperative lung function. Br I Anaesth 2012;109:263-71.

16 Shah B, Sucher K, Hollenbeck CB. Comparison of ideal body weight equations and published height-weight tables with body mass index tables for healthy adults in the United States. Nutr Clin Pract 2006;21:312-9.

17 Lellouche F, Dionne S, Simard S, Bussières J, Dagenais F. High tidal volumes in mechanically ventilated patients increase organ dysfunction after cardiac surgery. Anesthesiology 2012;116:1072-82.

18 Schultz MJ, Haitsma JJ, Slutsky AS, Gajic O. What tidal volumes should be used in patients without acute lung injury? Anesthesiology 2007;106:1226-31.

19 Quan H, Sundararajan V, Halfon P, Fong A, Burnand B, Luthi J-C, et al. Coding algorithms for defining comorbidities in ICD-9-CM and ICD-10 administrative data. Med Care 2005;43:1130-9.

20 Brueckmann B, Villa-Uribe JL, Bateman BT, Grosse-Sundrup M, Hess $\mathrm{DR}$, Schlett CL, et al. Development and validation of a score for prediction of postoperative respiratory complications. Anesthesiology 2013;118:1276-85

21 Bensley RP, Schermerhorn ML, Hurks R, Sachs T, Boyd CA, O’Malley AJ, et al. Risk of late-onset adhesions and incisional hernia repairs after surgery. J Am Coll Surg 2013;216:1159-67, 1167.e1-12.
22 Davenport DL, Henderson WG, Khuri SF, Mentzer RM. Preoperative risk factors and surgical complexity are more predictive of costs than postoperative complications: a case study using the National Surgical Quality Improvement Program (NSQIP) database. Ann Surg 2005;242:463-8; discussion 468-71.

23 Glance LG, Wissler R, Mukamel DB, LiY, Diachun CAB, Salloum R, et al. Perioperative outcomes among patients with the modified metabolic syndrome who are undergoing noncardiac surgery. Anesthesiology 2010;113:859-72.

24 Borzecki AM, Kaafarani HMA, Utter GH, Romano PS, Shin MH, Chen Q, et al. How valid is the AHRQ patient safety indicator "postoperative respiratory failure"? J Am Coll Surg 2011;212:935-45.

25 Lawthers AG, McCarthy EP, Davis RB, Peterson LE, Palmer RH, lezzon LI. Identification of in-hospital complications from claims data. Is it valid? Med Care 2000;38:785-95.

26 Utter GH, Cuny J, Sama P, Silver MR, Zrelak PA, Baron R, et al. Detection of postoperative respiratory failure: how predictive is the agency for healthcare research and quality's patient safety indicator? J Am Coll Surg 2010;211:347-54.

27 Heisler CA, Melton LJ, Weaver AL, Gebhart JB. Determining perioperative complications associated with vaginal hysterectomy: code classification versus chart review. J Am Coll Surg 2009;209:119-22

28 Grosse-Sundrup M, Henneman JP, Sandberg WS, Bateman BT, Uribe JV, Nguyen NT, et al. Intermediate acting non-depolarizing neuromuscular blocking agents and risk of postoperative respiratory complications: prospective propensity score matched cohort study. BMJ 2012;345:e6329.

29 Hess DR, Kondili D, Burns E, Bittner EA, Schmidt UH. A 5-year observational study of lung-protective ventilation in the operating room: a single-center experience. J Crit Care 2013;28:533.e9-15.

30 Jaber S, Coisel Y, Chanques G, Futier E, Constantin JM, Michelet P, et al. A multicentre observational study of intra-operative ventilatory management during general anaesthesia: tidal volumes and relation to body weight. Anaesthesia 2012;67:999-1008.

31 Royston P, Ambler G, Sauerbrei W. The use of fractional polynomials to model continuous risk variables in epidemiology. Int J Epidemiol 1999;28:964-74.

32 Sauerbrei W, Meier-Hirmer C, Benner A, Royston P. Multivariable regression model building by using fractional polynomials: description of SAS, STATA and R programs. Comput Stat Data Anal 2006;50:3464-85

33 Parsons LS. Reducing bias in a propensity score matched-pair sample using greedy matching techniques. In: Proceedings of the 26th Annual SAS Users. Paper. 2001;214-26.

34 Kurth T, Walker AM, Glynn RJ, Chan KA, Gaziano JM, Berger K, et al. Results of multivariable logistic regression, propensity matching, propensity adjustment, and propensity-based weighting under conditions of nonuniform effect. Am J Epidemiol 2006;163:262-70.

35 Van Buuren S. Multiple imputation of discrete and continuous data by fully conditional specification. Stat Methods Med Res 2007:16:219-42

36 Fernández-Pérez ER, Sprung J, Afessa B, Warner DO, Vachon CM, Schroeder DR, et al. Intraoperative ventilator settings and acute lung injury after elective surgery: a nested case control study. Thorax 2009;64:121-7.

37 Serpa Neto A, Hemmes SN, Barbas CS, et al. Protective versus conventional ventilation for surgery: a systematic review and individual patient data meta-analysis. Anesthesiology 2015; published online 15 May.

38 Amato MBP, Meade MO, Slutsky AS, Brochard L, Costa ELV, Schoenfeld DA, et al. Driving pressure and survival in the acute respiratory distress syndrome. N Engl J Med 2015;372:747-55.

39 The PROVE Network Investigators. High versus low positive end-expiratory pressure during general anaesthesia for open abdominal surgery (PROVHILO trial): a multicentre randomised controlled trial. Lancet 2014;384:495-503

40 Eikermann M, Kurth T. Apply protective mechanical ventilation in the operating room in an individualized approach to perioperative respiratory care. Anesthesiology 2015; published online 15 May.

41 Yilmaz M, Keegan MT, Iscimen R, Afessa B, Buck CF, Hubmayr RD, et al. Toward the prevention of acute lung injury: protocol-guided limitation of large tidal volume ventilation and inappropriate transfusion. Crit Care Med 2007;35:1660-6; quiz 1667

42 Schultz MJ, Haitsma JJ, Slutsky AS, Gajic O. What tidal volumes should be used in patients without acute lung injury? Anesthesiology 2007;106:1226-31

43 Wellman TJ, Winkler T, Costa EL, Musch G, Harris RS, Zheng $\mathrm{H}$, et al. Effect of local tidal lung strain on inflammation in normal and lipopolysaccharide-exposed sheep*. Crit Care Med 2014:42:e491-500.

(c) BMJ Publishing Group Ltd 2015

Appendix: supplementary tables and figures 